\title{
EDUCAÇÃO PROFISSIONALIZANTE POR MEIO DE HORTA COMUNITÁRIA NO ORFANATO MONTE MORIÁ DE UBERLÂNDIA-MG
}

Reginaldo de Camargo ${ }^{1}$, Anna Thereza Pereira Batista ${ }^{2}$, Leocadio Rezende Neto², Cleidson Aparecido Donizeti Tomaz ${ }^{2}$, Ana Luísa Alves Matos ${ }^{2}$

1 Professor associado do Instituto de Ciências Agrárias da Universidade Federal de Uberlândia (rcamargo@umuarama.ufu.br) Uberlândia - Brasil

2 Graduando(a) em Agronomia da Universidade Federal de Uberlândia

Recebido em: 08/09/2015 - Aprovado em: 14/11/2015 - Publicado em: 01/12/2015 DOI: http://dx.doi.org/10.18677/Enciclopedia_Biosfera_2015_268

\begin{abstract}
RESUMO
O projeto teve como objetivo determinar a viabilidade da inserção de ensino profissionalizante na área de olericultura para adolescentes abrigados em risco social. O projeto foi realizado numa cooperação entre a Universidade Federal de Uberlândia (UFU), por meio do Curso de Agronomia e a Direção do Orfanato Residencial Monte Moriá em Uberlândia-MG. Foi realizado o planejamento junto à direção da instituição, para a definição das espécies a serem cultivadas e do volume de hortaliças a ser produzido, em função da demanda e das aptidões de clima, solo e a estrutura do local. Foram selecionados dezesseis internos com idade entre doze e dezesseis anos com interesse em participar do trabalho. O preparo do solo e os tratos culturais na área foram realizados todo manualmente, com o auxílio dos discentes bolsistas do Curso de Agronomia da UFU e dos internos participantes. O treinamento ocorreu por meio de dois encontros por semana, com duração média de duas horas cada. As aulas tiveram um primeiro momento teórico, e, em seguida a realização de atividades práticas nos canteiros. Os participantes demostraram grande interesse pelas atividades desenvolvidas, sempre questionando e buscando cumprir as ações propostas. Notou-se sensível mudança no comportamento de alguns internos durante 0 projeto, assumindo responsabilidades $\mathrm{e}$ inclusive repassando conhecimentos adquiridos aos demais colegas. A atividade demostrou ter potencial para colaborar com a formação cidadã, socialização e qualidade de vida dos internos participantes.
\end{abstract}

PALAVRAS-CHAVE: agricultura, cidadania, educação

\section{ADDITIONAL TRAINING IN VOCATIONAL EDUCATION AND PRODUCTION OF VEGETABLES IN THE ORPHANAGE MONTE MORIAH OF UBERLÂNDIA-MG ABSTRACT}

The project aimed to determine the feasibility of vocational insertion in the horticulture area for teenagers housed in social risk. The project was carried out in cooperation between the Federal University of Uberlandia (UFU), through the Agronomy course and direction of the Orphanage Residential Monte Moriah in Uberlandia, Minas Gerais. It was done planning along the direction of the institution, to define the species to be cultivated and the volume of vegetables to be produced, 
depending on the demand and the weather skills, soil and the structure of the site. Sixteen inmates were selected aged between twelve and sixteen years with interest in participating in the work. The soil preparation and cultivation in the area were carried out all manually, with the help of scholarship students of the UFU Course Agronomy and internal participants. The training took place through two meetings per week, with an average duration of two hours each. Classes have an initial theoretical moment, and then performing activities in practice sites. The participants have shown great interest in the activities developed, always questioning and seeking to meet the proposed actions. It was noted a significant change in the behavior of some built during the project, taking responsibility and even passing on knowledge acquired to other colleagues. The have demonstrated potential activity to collaborate with civic education, socialization and quality of life of participants inmates.

KEYWORDS: agriculture, citizenship, education

\section{INTRODUÇÃO}

O acolhimento em abrigos tem que ser excepcional e provisório, tendo sempre em vista o retorno da criança ou do adolescente à sua família de origem no mais breve prazo possível. Os abrigados têm o direito de manter os vínculos com suas famílias e estas necessitam de apoio para receber seus filhos de volta e conseguir exercer suas funções de forma adequada.

Enquanto as crianças e os adolescentes permanecem nos abrigos, o artigo 92 do Estatuto da Criança e do Adolescente (ECA) Ihes assegura o direito à convivência familiar e comunitária, que pode lhes ser garantido também pela colocação em família substituta ou pela vivência em instituições acolhedoras e semelhantes a residências, que proporcionem um atendimento individualizado e personalizado. Ao contrário do que muitos pensam, a maioria dos abrigados $(86,7 \%)$ tem família e apenas $5,2 \%$ são órfãos (MPF, 2015). Assim, durante o período em que permanecem abrigados, seja por um curto ou longo período de tempo, o contato com projetos ou programas profissionalizantes é muito importante, abrindo portas para um futuro emprego e consciência cidadã.

A construção de uma horta comunitária permite além de práticas alimentares saudáveis, ricas em vitaminas e minerais, abordar questões relativas à cidadania e preservação ambiental. O planejamento participativo é um processo contínuo de construção e avaliação, que possibilita o resgate da auto-estima e cidadania de seus integrantes. A melhoria na qualidade de vida tem sido buscada na interação homem e ambiente e o processo educativo tem sido um canal de transformações social, cultural e econômica. Conforme CRIBB (2010), cada vez é mais evidente a importância de uma educação de qualidade que leve em consideração a formação de cidadãos mais críticos, responsáveis e capacitados para a vida. Nesse sentido, cresce no Brasil, principalmente a partir do século $\mathrm{XXI}$, a demanda por políticas educacionais que possibilitem a inclusão educacional de diferentes grupos. Tendo em vista suprir lacunas na sua formação, bem como oferecer uma formação que viabilize suas necessidades sociais e laborais aos jovens e adultos, uma educação que promova sua efetiva profissionalização articulada a uma formação cultural que permita compreender e transformar a realidade social em que se encontram (PEREIRA, 2011). Além do cultivo de hortaliças, a produção de plantas medicinais tem sido empregada na educação em escolas e como instrumento complementar para tratamento de pacientes com sofrimento mental. Segundo Arnous et al. (2005), a participação social na produção da 'farmácia verde' comunitária deve ser estimulada, com envolvimento das prefeituras, secretarias de saúde e agricultura, 
associações comunitárias e instituições de ensino, pesquisa e extensão, para aproveitamento integral dos benefícios.

Além da conscientização de uma melhor alimentação isso possibilita a capacitação profissional das pessoas envolvidas, permitindo que as mesmas possam produzir seu próprio alimento e tenham acesso a técnicas de produção de hortaliças. CAPORAL et al. (2011) consideram que a educação envolve os processos de capacitação, não como mero adestramento, mas como busca de conhecimento.

Considerando que o ensino de práticas de agricultura também pode ser inserido no ambiente de um abrigo de adolescentes, objetivou-se implantar uma metodologia de capacitação de jovens e adolescentes em risco social, internados no Orfanato Monte Moriá de Uberlândia-MG e aperfeiçoamento em extensão rural e olericultura de graduandos do Curso de Agronomia.

\section{MATERIAL E METODOS}

Para a realização do projeto foi efetuado um planejamento junto à direção do Orfanato Monte Moriá, das espécies hortícolas que foram cultivadas e do volume a ser produzido, em função da demanda diária da instituição e das aptidões de clima solo, e a estrutura do local. A instituição disponibilizou uma área com aproximadamente $1000 \mathrm{~m}^{2}$ protegida por tela, no interior do orfanato apta para a instalação da horta. Com a orientação da equipe de assistentes sociais, foram selecionados dezesseis adolescentes internos com idades entre doze e dezesseis anos para participação no projeto, os quais possuíam disponibilidade de horário, fora dos horários em que frequentavam o ensino básico ou médio nas escolas do estado ou município.

O preparo do solo e os tratos culturais na área foram realizados manualmente pelos adolescentes com o auxílio de dois discentes bolsistas e dois voluntários do Curso de Agronomia da Universidade Federal de Uberlândia (UFU), sob a supervisão de um professor. A correção e adubação do solo foram feitas com calcário e fertilizantes orgânicos e químicos, com base no resultado da análise de química do solo. As plantas daninhas foram manejadas quimicamente.

O treinamento dos internos ocorreu num período de 24 meses por meio de dois encontros por semana, com duração de duas horas cada. As aulas apresentavam sempre um primeiro momento teórico, e em seguida a realização de atividades práticas nos canteiros, além de eventuais atividades fora do horário das aulas regulares programadas.

Contando com mais de cinquenta internos, a maior parte da produção era consumida na no próprio orfanato, sendo o excedente doado para outras instituições.

A avaliação do projeto ocorreu permanentemente por meio de acompanhamento de frequência, e interesse dos internos cadastrados na realização das atividades programadas. A equipe de psicólogos do orfanato elaborou um planejamento para análise individual dos participantes, quanto a possíveis mudanças comportamentais de correntes do desenvolvimento das atividades. Em relação aos alunos bolsistas ocorreram reuniões semanais para avaliação dos resultados das aulas teóricas e práticas. 


\section{RESULTADOS E DISCUSSÃO}

O projeto foi muito bem recebido pelos funcionários da instituição, mas especialmente pelas crianças e adolescentes abrigados no Orfanato Monte Moriah, uma vez que nenhuma atividade desta natureza havia sido desenvolvida até então naquela instituição. Na primeira reunião $\mathrm{com}$ a comunidade da instituição foram destacados pela equipe executora todos os cuidados acerca de se evitar acidentes decorrentes dos trabalhos na horta.

Da mesma forma, a instituição apresentou os cuidados mais importantes quanto a forma de abordagem e relacionamento com os internos. Estabeleceu-se que a participação seria voluntária dentre os que estivessem aptos para a realização da capacitação, entretanto, seria cobrado o compromisso quanto à frequência e dedicação.

Conforme destaca KONKIEWITZ (2013), o estabelecimento de regras e limites é uma necessidade para a educação de qualquer individuo e significa cuidado e afeto pelo outro. Toda criança e/ou adolescente precisa de uma referencia e um modelo de comportamento adequado. $\mathrm{O}$ ambiente familiar deve ser facilitador e continente as necessidades afetivas e educacionais de nossas crianças e adolescentes.

A escola é a segunda e mais importante instituição, depois da família. É na escola que a aprendizagem tem continuidade e as relações sociais acontecem. Foi observado que os adolescentes participantes do projeto demostravam respeito pelos coordenadores das atividades, a ponto de em vários momentos repreender os próprios colegas quando a necessidade de silêncio e organização.

Desde a definição das delimitações da horta, construção da cerca e limpeza da área (Figura 1), todas as tomadas de decisões sempre levaram em conta o ponto de vista dos internos participantes do projeto, como forma de colaborar no desenvolvimento do estímulo a que ficasse bem compreendido o aspecto de parceria, colaboração e respeito às diferentes opiniões. Em muitos momentos, chamou a atenção da equipe, o prévio conhecimento por parte dos internos, de praticas de agricultura, subentendendo-se que alguns possivelmente mantinham em diferentes níveis, algum tipo de convívio com a agricultura em suas residências de origem.

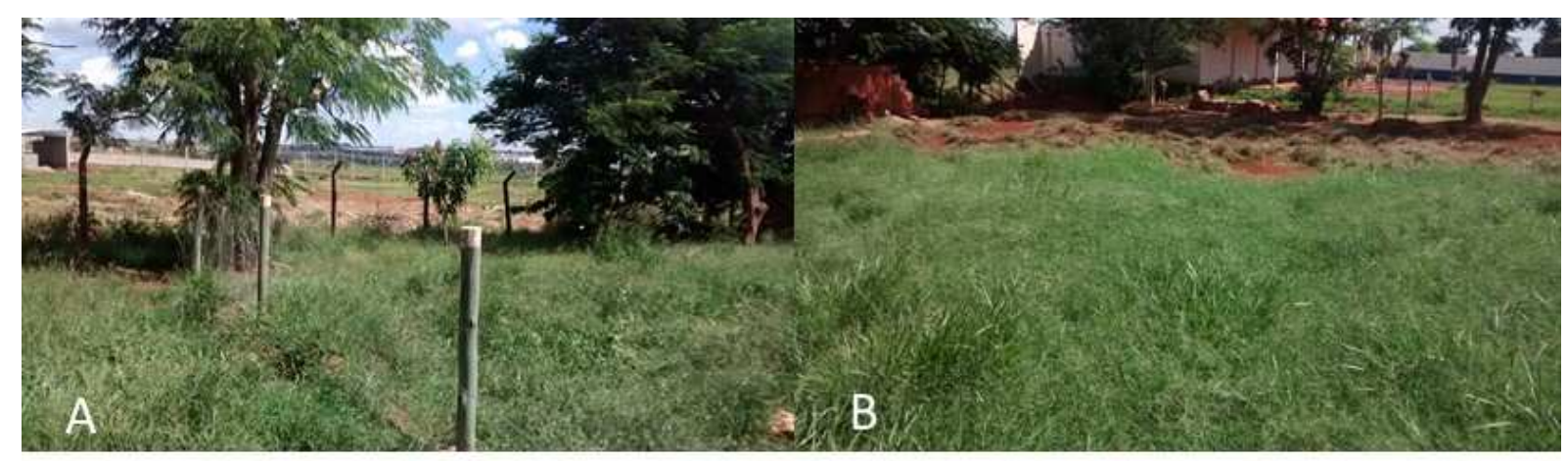

FIGURA 1: a) Instalação da cerca de delimitação da horta no Orfanato Monte Moriah; b) Capina manual e limpeza da área da horta.

Conforme o manual de Orientações Técnicas: Serviços de Acolhimento para Crianças e Adolescentes (BRASIL, 2009), a organização dos serviços dentro de uma 
instituição desta natureza deverá garantir proteção e defesa a toda a criança e adolescente que precise de acolhimento. Devem ser combatidas quaisquer formas de discriminação às crianças e aos adolescentes atendidos em serviços de acolhimento e às famílias de origem, baseadas em condição socioeconômica, arranjo familiar, etnia, religião, gênero, orientação sexual, ou, ainda, por serem pessoas com necessidades especiais.

Em atenção ao princípio da não discriminação, os serviços de acolhimento devem buscar o crescente aprimoramento de estratégias voltadas à preservação da diversidade cultural, oportunizando acesso e valorização das raízes e cultura de origem das crianças e dos adolescentes atendidos, bem como de suas famílias e comunidades de origem. Neste sentido, conforme orientações da coordenação da instituição, o trabalho da equipe responsável pelo projeto limitava-se as atividades de ensino de práticas agrícolas, evitando discussões acerca de outros temas. Ainda de acordo com as normas da instituição, foi solicitado que não fossem feitas fotos ou imagens das crianças e adolescentes durante a realização das atividades do projeto.

Após a limpeza da área, a participação direta dos adolescentes ocorreu em todas as fases do projeto, incluindo a construção dos canteiros (Figuras 2 A e 2B), semeio, capina, tratos culturais e colheita.

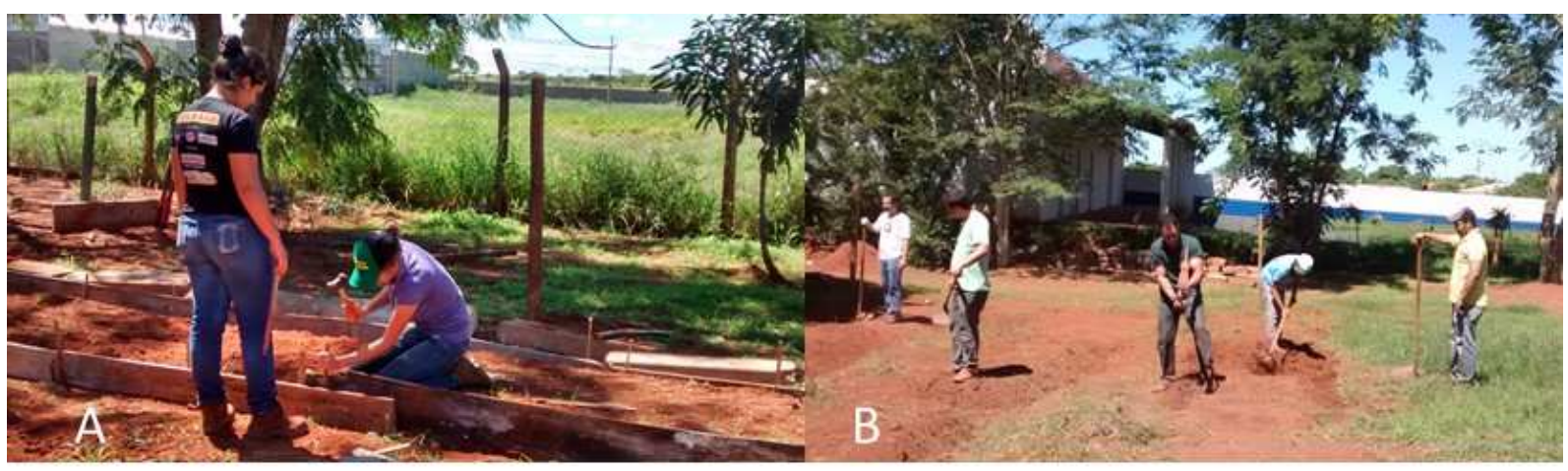

FIGURAS 2A e 2B: Preparo dos canteiros para instalação dos cultivos.

A partir das primeiras aulas teóricas onde foi apresentado o projeto da horta, notou-se grande dificuldade em prender a atenção dos participantes com o uso de data show e aula expositiva em sala da aula, o que em parte a equipe atribuiu, com fundamento no relato dos adolescentes, ao fato de representar uma segunda jornada nos estudos, uma vez que todos permaneciam metade do dia em sala de aula em suas escolas. Desta forma, optou-se por apresentar o conteúdo teórico de forma mais resumida, no próprio local da horta, momentos antes da realização das atividades de cada dia. Embora tenha havido um decréscimo na apresentação de fotos, vídeos e detalhes mais específicos relativos a cada tópico de estudo, foi observado que houve um menor grau de abstração e maior interesse em compreender as tarefas que seriam executadas logo a seguir.

Após a limpeza, delimitação da área da horta e construção dos canteiros, o entorno do local passou por uma revitalização com a participação dos internos, por meio de pintura de bancos para descanso e poda de árvores. Destaca-se, conforme relato dos participantes, que a horta trouxe uma melhor aparência a um local antes abandonado e passou a efetivamente a servir de abrigo para a realização de brincadeiras e leituras (Figuras 3A e 3B).

De acordo com LIMA e AMORIM (2015), a falta de arborização, por exemplo, pode trazer desconforto térmico e possíveis alterações no microclima, e como essas 
áreas também assumem papel de lazer e recreação da população, a falta desses espaços interfere na qualidade de vida desta. Aos visitantes, incluindo familiares dos internos e entidades filantrópicas e religiosas colaboradoras da instituição, o local passou também a ser mais utilizado.

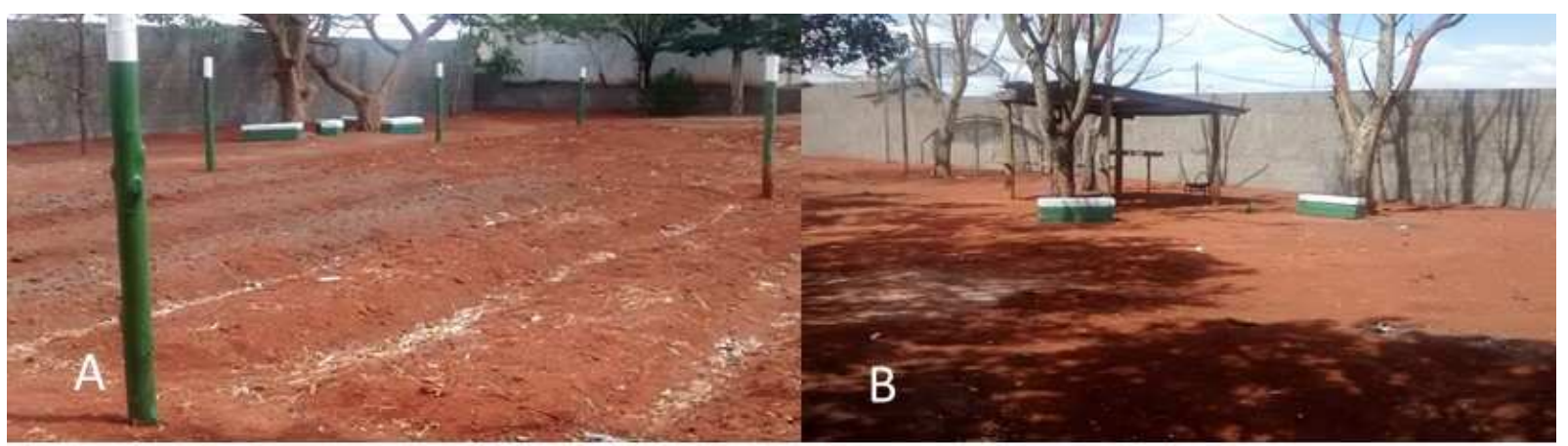

FIGURAS 3A e 3B: Recuperação no entorno da horta e instalação de bancos para leitura.

Ao longo do período de duração do projeto houve a saída de seis internos motivada pelo retorno ao convívio familiar, entretanto todos puderam acompanhar toda a fase de instalação da horta e no mínimo um ciclo de cultivo de hortaliças. As principais espécies produzidas foram: alface, cenoura, couve, rúcula, cebolinha, abóbora e rabanete. Assim, sempre que havia necessidade, novos internos eram integrados ao grupo, passando a desenvolver as atividades conforme planejamento.

$\mathrm{Na}$ avaliação da equipe psicológica da instituição, o trabalho desenvolvido na horta foi muito positivo em relação a melhorias no comportamento de alguns internos. A ocupação passou a diminuir o tempo ocioso e gerar o sentimento de responsabilidade. Um estudo feito pela Sociedade para Pesquisa do Desenvolvimento da Criança, nos Estados Unidos, mostrou que enquanto $40 \%$ dos meninos e meninas entre 5 e 18 anos não tinham nenhuma atividade fora da escola, entre $3 \%$ e $6 \%$, gastavam vinte horas por semana em cursos e aulas antes ou depois do horário escolar. Não por acaso, eram justamente esses últimos os que demonstravam melhor preparo educacional e psicológico. Estimular o raciocínio significa aprimorar o desenvolvimento das crianças, o que resulta em adolescentes seguros e adultos bem-sucedidos (EDUCAR PARA CRESCER, 2015).

Após os primeiros ciclos de cultivo das hortaliças, os internos passaram a desenvolver as atividades sem necessidade constante de orientação dos bolsistas do Curso de Agronomia, aplicando os conhecimentos adquiridos, questionando e em diversas situações propondo adequações, como por exemplo, a redução ou aumento do número de canteiros de determinadas espécies e mudanças nos locais de canteiros.

Relativo aos graduandos em Agronomia que participaram do projeto, bolsistas ou voluntários (Figura 4) observações do coordenador do trabalho e relatos destes alunos permitem afirmar que a atividade foi muito importante na aquisição e fixação de princípios de extensão rural. $O$ contato com os internos da instituição proporcionou ainda a oportunidade do desenvolvimento de habilidades de argumentação e disciplina. Em acréscimo, foi necessário estudo periódico sobre técnicas de produção de hortaliças, fitopatologia e fertilidade do solo, muito necessários para a condução do sistema de produção adotado. 


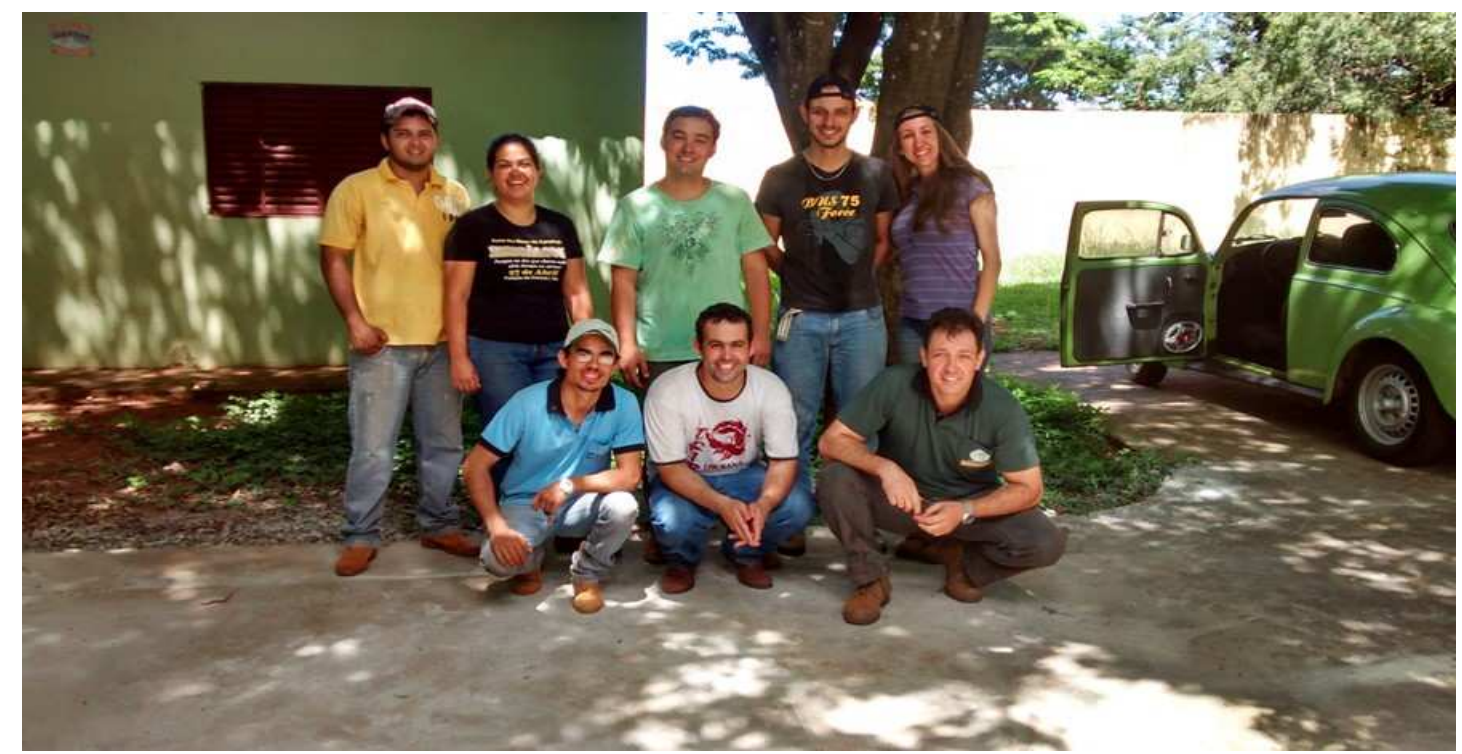

FIGURA 4: Graduandos do Curso de Agronomia que participaram do projeto.

\section{CONCLUSÕES}

A atividade de horticultura integrada à rotina do orfanato mostrou-se efetiva, colaborando com melhorias no comportamento e qualidade de vida dos internos em função do maior consumo de verduras e legumes.

\section{AGRADECIMENTOS}

Fundação de Amparo à Pesquisa do Estado de Minas Gerais.

\section{REFERÊNCIAS}

ARNOUS, A.H.; SANTOS, A.S.; BEINNER, R.P.C. Plantas medicinais de uso caseiro-conhecimento popular e interesse por cultivo comunitário. Revista Espaço para a Saúde, v.6, n.2, p.1-6. Londrina, 2005.

BORBA, S.N.S.; VARGAS, D.L.; WIZNIEWSKY, J.G. Promovendo a educação ambiental e sustentabilidade através da prática da agricultura de base ecológica. Disponível em: http://cascavel.ufsm.br/revistas/ojs2.2.2/index.php/revistadireito/article/viewFile/8390/5080. Acesso em: 28 de maio de 2015.

BRASIL. MINISTÉRIO DO DESENVOLVIMENTO SOCIAL E COMBATE A FOME. Orientações Técnicas: Serviços de Acolhimento para Crianças e Adolescentes. Brasília, 2009, 105p.

CAPORAL, F. R.; COSTABEBER, J. A.; PAULUS, G. Agroecologia: matriz disciplinar ou novo paradigma para o desenvolvimento rural sustentável. Visualizado em http://www.agroeco.org. Acessado em abril de 2012. 
CRIBB, S. L. S. P. Contribuições, da educação ambiental e horta escolar na promoção de melhorias ao ensino, à saúde e ao ambiente. REMPEC- Ensino, Saúde e Ambiente, v.3, n.1, p. 42-60, 2010.

EDUCAR PARA CRESCER. Como escolher um curso extracurricular para meu filho? Disponível em: http://educarparacrescer.abril.com.br/aprendizagem/atividades-extras-618810.shtml. Acesso em 11 de junho de 2015.

KONKIEWITZ, E.C. Aprendizagem, comportamento e emoções na infância e adolescência: uma visão transdisciplinar. Dourados-MS, Ed. UFGD, 2013. 312p.

LIMA, V.; AMORIM, M.C.C.T. A importância das áreas verdes para a qualidade ambiental das cidades. Revista Formação, n.13, p. 69 - 82, 2006.

MINISTÉRIO PÚBLICO FEDERAL. Como é a vida de crianças e adolescentes nos abrigos? Disponível em: http://www.turminha.mpf.mp.br/direitos-dascriancas/convivencia-familiar-e-comunitaria. Acesso em: 11 de março de 2015.

PEREIRA, J. V. O. Proeja no Instituto Federal de Goiás - Campus Goiânia: um estudo sobre os fatores de acesso e permanência na escola. 2011. Dissertação (Mestrado em Educação) - Faculdade de Educação, Universidade de Brasília, DF. 2011.

Universidade do Oeste Paulista - UNOESTE. Cultivo de hortaliças em vasos é ensinado para adolescentes, 2012. Disponível em: http://unoeste.br/site/noticias/2012/11/cultivo - de-hortalicas-em-vasos-e-ensinadopara-adolescentes.htm. Acesso em: 17 de abril de 2015. 